\title{
Validation of Requirements for Transformation of an Urban District to a Smart City
}

\author{
Rosziati Ibrahim $^{1}$, N.A.M. Asri ${ }^{2}$ \\ Department of Software Engineering \\ Universiti Tun Hussein Onn \\ Malaysia (UTHM) \\ Parit Raja, Malaysia
}

\author{
Sapiee Jamel ${ }^{3}$ \\ Dept. of Web Technology and \\ Information Security \\ Universiti Tun Hussein Onn \\ Malaysia (UTHM) \\ Parit Raja, Malaysia
}

\author{
Jahari Abdul Wahab ${ }^{4}$ \\ Engineering R\&D Department \\ SENA Traffic Systems Sdn. Bhd \\ Kuala Lumpur, Malaysia
}

\begin{abstract}
The concept of a smart city is still debatable and yet gives attention to every country around the globe to provide their community with a better quality of life. New ideas for the development of a smart city have always evolved to enhance the quality, performance, and interactivity of services. This paper presents a model of a smart city based on the comparison of the chosen smart cities in the world and used the model to validate the requirements for the transformation of an urban district to a smart city. The proposed model for a smart city in this paper focuses on two major components, which are by utilizing IoTs (Internet of Things) in forming a model for a smart city and incorporating culture diversity. The relationship of components and culture influence are the foundation of designing the model of a smart city. In this research, the model of a smart city has been validated based on the requirements analysis from the survey instrument and the results show that the average mean of each element used is more than 4 out of 5 . The model of a smart city can be used as a guideline for transformation of an urban district to a smart city.
\end{abstract}

Keywords-Smart city; Internet of Things (IoTs); requirements analysis; survey instrument

\section{INTRODUCTION}

The smart city development has been growing over years, with the concept highly debated in all countries. A smart city is the answer to the rise of globalization of cities by managing and implementing ICT (information and communication technology) in all dimensions of the city such as infrastructure, mobility, governance, buildings, health and education. A smart city has become a competition between countries to serve the best for its citizens. The development has become dilemmas for the governance as it is a long-term process, which requires a lot of hard work between public and private sector. A smart city [1] is defined as a city that has components for smart such as smart citizen, smart infrastructure, smart building, smart governance, smart transportation, smart technology, smart health care and smart energy. A smart city does not necessarily have all these components to label as smart but depends on the cost and availability of the technology.

The components of smart city have been discussed by many researchers such as in [1 - 5]. However, as far as the research on smart city, no smart urban district model has been formed yet. Therefore, the design of smart urban district model is important leading to a research question on how to design a smart urban district model. To answer this research question, the objectives of the research is to design a smart urban district model and to validate the model based on the survey instrument so the model can be used as a guideline for the transformation of an urban district to a smart city.

This paper discusses the validation of requirements for a model of a smart city. Survey instruments are used to validate the model. The survey consists of questionnaire, interview and observation at research area. The questionnaire is divided into five sections which are demographic data, awareness of a smart city, elements of a smart city, impact of forming a smart city and culture influence towards a smart city with the purpose to ease the researcher to analyze the data. Interviews and surveys are conducted to people who live within the research area. The data has been collected and analyzed using Statistical Package for the Social Sciences (SPSS) software.

\section{RELATED WORK}

In Malaysia, Putrajaya has been proposed as a first smart city in Malaysia. Seven domains have been considered as important elements to make Putrajaya as a smart city [2]. These seven domains are highlighted in Fig. 1.

From Fig. 1, smart transportation and mobility are the first domain for making Putrajaya as a smart city by adopting an intelligent traffic management system [3]. Smart home and environment ensure the residents of Putrajaya safety, which include intelligent environments by utilizing Internet of Things (IoTs) such as Wi-Fi, CCTV, and RFID.

The architecture of smart city has been discussed in [4]. From the architecture that have been suggested in [4], there are four requirements which are infrastructure, IoTs, environment and culture as shown in Fig. 2. Based on the architecture proposed in [4], the model of smart city has four elements, which are infrastructure, IoTs, environment and culture elements. Infrastructure consists of hospital, school, recreation park and library while IoTs consists of WSN Wifi, CCTV, Smart Parking and RFID. Meanwhile, environment consists of waste management, renewable resource energy, waste management and recycling program and lastly, culture element consists of prayer place and town hall.

This work was supported by Minister of Higher Education (MOHE) under Fundamental Research Grant Scheme (FRGS) under grant Vote No FRGS/1/2018/ICT04/UTHM/01/1. 


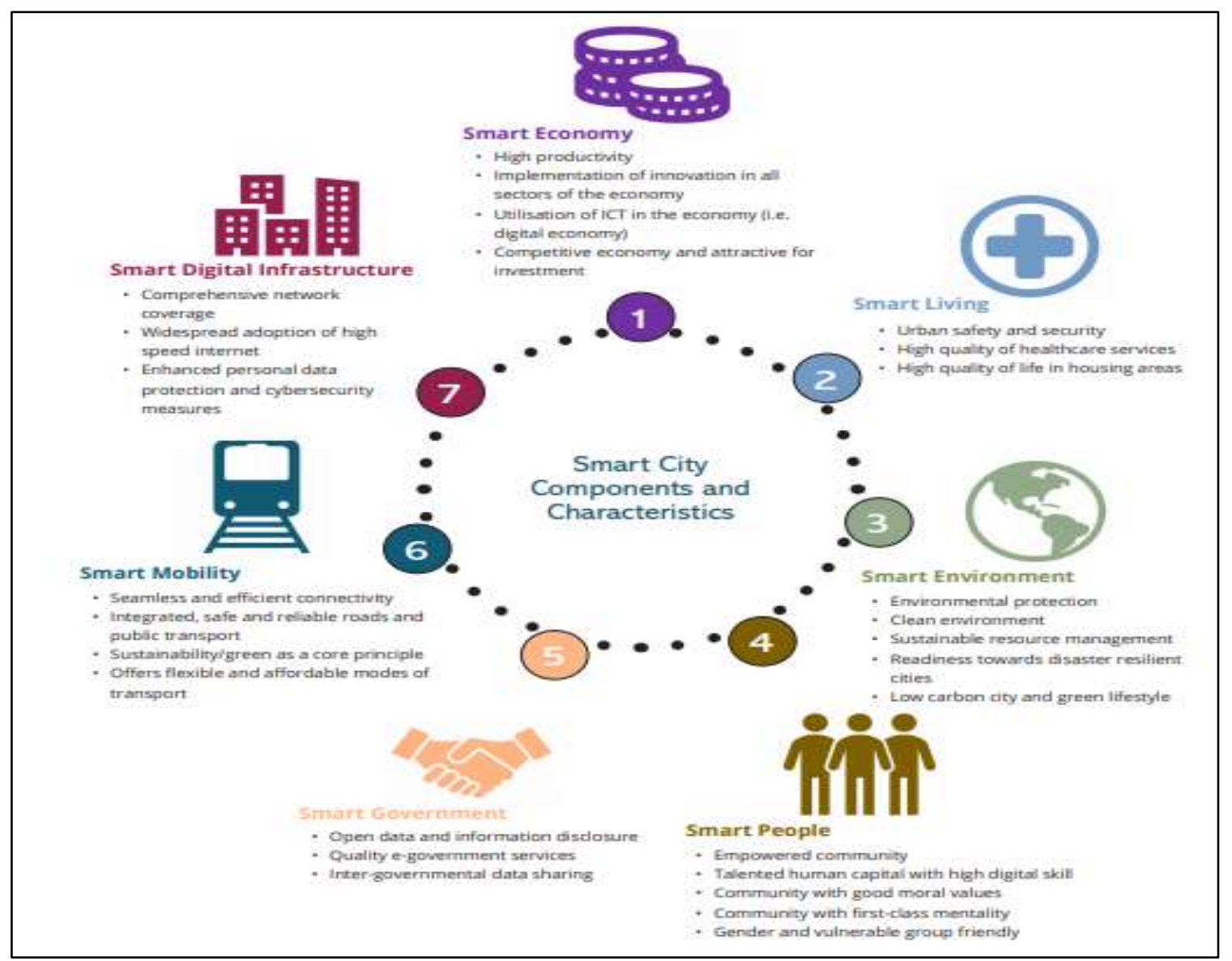

Fig. 1. Putrajaya Smart City Framework [2].

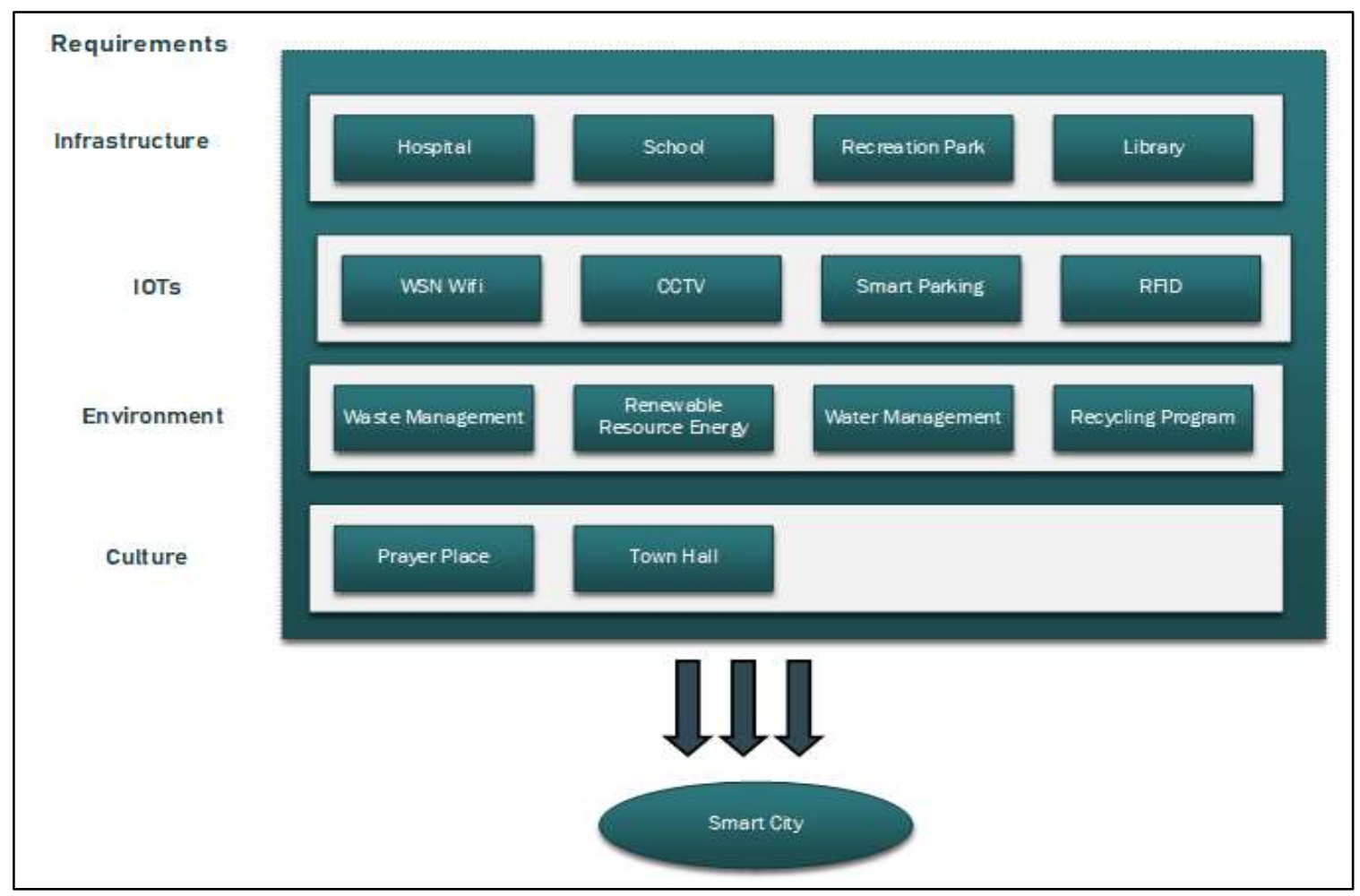

Fig. 2. The Architecture of a Smart City [4]. 
The proposed architecture in [4] was drawn from various studies such as [5] and [6]. Table I shows the summary of elements that have been cited by various researchers. The details clarifications are explained.

TABLE I. SUMMARY OF ELEMENTS

\begin{tabular}{|l|l|}
\hline Elements & References \\
\hline Infrastructure & {$[5],[6],[7],[8]$} \\
\hline IoTs & {$[9],[10],[11],[12],[13]$} \\
\hline Environment & {$[12],[13],[14]$} \\
\hline Culture & {$[14],[15]$} \\
\hline
\end{tabular}

\section{A. Infrastructure}

Infrastructure has positively affected the smart city. The population growth has adapted to cities' services and infrastructures that tension to their limits and scalability. To build a smart city, the long-term scalability in term of housing, accessibility, transport system and sustainable growth should have taken into consideration in order to make a better life. Infrastructure in a smart city surround by the evolvement of all aspects of modern-day life such as transportation, healthcare, entertainment, work, business, social interactions, and governance [5 - 7].

Infrastructure defined broadly as the systems that provide water, energy, food, sheleter, transportation, communication, waste management and public spaces [6]. Khatoun et al. [7] stated that for sustainability and accessibility the development and growth from a city, the resource management such as safety and security, environment and transport, educational facilities, tourism and citizen's health are important to provide efficiency of urban life.

\section{B. IoTs}

The main engine for a smart city delivery is its technology. The technology drives the ICT and IoTs to make it more immersive and permissive. IoTs work amazingly in heterogeneous devices to communicate among those platforms to support smart city's vision in maximal exploits in communication.

IoTs links physical devices such as computer, sensors, electronics equipped with sensors connected to the internet and network connectivity enabling them to communicate [8]. Gartner [9] mentioned the IoTs units installed based will reach 20.8 billion by 2020 resulting in massive amount of data which will further highlight the security, customer privacy, storage management, and data centric network challenges.

Chang et al. [10] stated that the growing ubiquity and emerging applications of IoTs, especially in urban centres will enhance the usefulness of such systems to transform the manner in which social entities like individuals and organisations such as schools, healthcare, families, and community groups to interact with one another and their physical environment. IoTs connect everything together via the internet through specific protocols for information exchange and communications, achieving intelligent recognition, location, tracking, monitoring, and management. By interconnecting physical and virtual worlds with huge amounts of electric devices distributed in houses, vehicles, streets, buildings, and many other public environments, it can help in various kinds of services for both citizens and administrators [11].

\section{Environment}

Zygiaris [12] stated in his paper there is 7 layers for smart city conceptual model and of them is the green city layer that should practice in taking other alternative energy for city planning, water conservation, green transport practices, green building policies and $\mathrm{CO} 2$ reduction.

Tangauay et al. [13] included environment element in their dimensions of sustainable development of a smart city. To correspond to the concept of a quality of life, he studied indicators for sustainable development in an urban setting. They found that environmental challenges such as water pollution, soil contamination and air pollution can discontinuities the structural changes of the place.

Environment linked with natural resources and energy such as renewable energies, waste management and water management. Waste management focused on collecting, recycling, and disposing waste in correct ways; water management to analyze and manage the quantity and quality of water through hydrological cycle; renewable energy which exploits the natural resources that are regenerative such as heat, water and wind power [14].

\section{Culture}

A smart city rarely related with the culture of a city. Most researchers $[5,6,8,9]$ are mostly focus on other elements without taking culture element into consideration. Culture can build a city in term of raising the quality of life which encourage celebration in a way expressing creativity and show the individual identity and enhance or preserve the community's sense of place. Public involvement in exploiting the culture and attractiveness of a city's cultural heritage can facilitate in maintaining the attractive of a city [14].

Allam and Newman [15] highlighted that a smart city usually focused on ICT without taking cultural values into deliberation as it holds the legacies of the city. Their research proposed a framework that requires culture into consideration along with governance elements. Culture can contribute vitally to the economic growth as most visitors are attracted to one's cultural events. They also said the potential culture factor can revamp the urban areas.

\section{RESEARCH METHODOLOGY}

In this study, we have conducted an interview in the domain of the area. An interview is widely used in conducting research which requires a face-to-face interaction between an interviewee and an interviewer. An interview occurs when an interviewer asks one or more participants in general, open ended questions and record their answers [16]. Interviews are beneficial for getting the information behind a participant's experiences or knowledge. According to Giacoppo [17], interviews are also useful for pinpoint any potential areas for more detailed analysis. 


\section{A. Preliminary Study}

A questionnaire is defined as a document containing questions and other types of items designed to solicit information appropriate to analysis [18]. During preliminary study, questionnaire design, questionnaire validation, pilot study, instrument reliability test, sample size population has been performed. After the collection of data, questionnaire response rate has been calculated. The questionnaire was designed based on closed-ended questions. Five-point LikertType scale [19] is used for this questionnaire to determine the degree of agreement of the respondents with the statements. They are Strongly Disagree, Disagree, Neutral, Agree and Strongly Agree.

Creswell [20] recommended that studies which involved in making questionnaires and interview must run a pilot study to modify the instruments based on feedback of small pool of respondents. A pilot study aims to reveal and eliminate the weakness of questionnaires [21]. A set of questionnaires were designed based on information from related prior studies which had investigated the elements of a smart city. The pilot study was carried out to examine each element and to test the feasibility of questionnaires. This study is necessary to verify the elements in the questionnaire whether they are reliable and free of errors. Therefore, for this study, the researchers had sent a set of questionnaires to 30 respondents for them to answer for the pilot study.

Reliability test is used for evaluating the reliability of the questionnaire based on Cronbach's alpha [22]. Table II shows the results for testing the reliability of the questionnaire.

TABLE II. INSTRUMENT RELIABILITY

\begin{tabular}{|l|l|l|}
\hline Factor & Cronbach's alpha & No. of Items \\
\hline Infrastructure & 0.938 & 4 \\
\hline IoTS & 0.877 & 4 \\
\hline Environment & 0.891 & 4 \\
\hline Culture & 0.940 & 2 \\
\hline
\end{tabular}

Based on Table II, the Cronbach's alpha is greater than 0.7 for each element, hence the questionnaire is acceptable.

For the validation of the requirements for the model of a smart city, a total of 400 questionnaires were distributed in Sri Gading. From the total, only 391 questionnaires were received, and 374 questionnaires are able to be used. The remaining questionnaires cannot be used because of incomplete answers and missing information in several areas. Table III shows the questionnaire response rate for this study.

TABLE III. QUESTIONNAIRE RESPONSE RATE

\begin{tabular}{|l|l|}
\hline Description & Frequency \\
\hline Total Distributed Questionnaire & 400 \\
\hline Total Received & 391 \\
\hline Percentage of Response Rate & $97.75 \%$ \\
\hline Usable Questionnaires & 374 \\
\hline Adjusted Response Rate & $93.5 \%$ \\
\hline
\end{tabular}

\section{B. Data Analysis}

During the data analysis phase, data preparation that involves screening, checking missing data, suspicious response rate, outliers, and normality have been analysed. Data preparation performed to determine how to assign the numeric scores to the data. Before the process of analysing the data can be done, cleansing the data is important to ensure data is free from any error. Screening, checking missing data, suspicious response rate, outliers and normality are steps in preparing a valid data. The data is screened to detect and delete any kind of undesired data. The data were coded with characters and numbers and the responses were key in manually using SPSS. After that, the missing data is checked to overcome any error before proceeding with data analysis. SPSS is used to check the missing data. The result found that $0.431 \%$ is missing responses. Research analysis is acceptable if the neglecting responses with missing values are less than $10 \%$ [21].

The suspicious response rate has been identified for all dataset. The result found out that there is no suspicious response rate and can be considered error free. Suspicious response rate is the identification of the response pattern by the respondents which mark similar answer for all questions [22]. Outliers are to state the error rates and substantial distortions of parameter and statistic estimates when using either parametric or nonparametric tests [23]. This step was achieved by examining each individual construct using standard score. To analyze outliers, standardized Z-scores is created for the variables and the values are examined. If the $\mathrm{Z}$-scores ranged between -3.29 and +3.29 , it indicates no outliers [22]. Table IV shows the result of outliers analyzation. The Z-scores range is between -3.29 and +3.29 , thus, no outliers are found in this dataset. Therefore, the data set is free from error.

\section{TABLE IV. OUTLIERS}

\begin{tabular}{|l|l|l|l|}
\hline Construct & Max & Min & Outliers \\
\hline Infrastructure & 2.90 & 0.94 & No \\
\hline IoTs & 3.16 & 0.97 & No \\
\hline Environment & 3.21 & 1.14 & No \\
\hline Culture & 2.66 & 1.11 & No \\
\hline
\end{tabular}

Normality is used to regulate whether the data is wellmodelled according to normal distribution. Holmes et al. [23] suggested that each construct item needs to be analyzed for their normalization. Value of skewness and kurtosis function estimate the symmetry and peak of data distribution. We tested our questionnaire for this and the standard error of skewness is 0.203 and the value of standard error of kurtosis is 0.403 . The skewness for a normal distribution is zero, and any symmetric data should have a skewness near zero. Thus, this shows that standard error of skewness and kurtosis is not too far from normal distribution.

\section{Statistical AnAlysis AND Results}

The results based on the survey instrument are discussed in this section. Descriptive statistics are used to illustrate the data in two ways which are demographic frequencies and descriptive statistics and variables. The data has been analysed 
using statistical software, SPSS. Table V shows the demographic information obtained from the questionnaire.

Table $\mathrm{V}$ also shows the statistic of demographic frequencies of the respondents. A total number of 374 questionnaires were analyzed after eliminating the uncompleted data. Based on Table V, the respondents' characteristics include gender, race, occupation, income and residency. These characteristics were considered to provide indepth understanding of the respondents.

Based on Table $\mathrm{V}$, most of the respondents are dominated by females by $223(59.6 \%)$ and 151 are males (40.4\%). Most of them are Malay which $344(92 \%)$, followed by Chinese is $19(5.1 \%)$; Indian is $3(9 \%)$ and others 4 people $(2 \%)$. Most of them aged between 41 to $50(31 \%) ; 24.3 \%$ from age 31 to 40 , $23.3 \%$ from age over 50 years old followed by $12.8 \%$ for aged between 21 to 30 and $8.6 \%$ from under 20 years old. For occupation, respondents mostly are from private sector $(37.2 \%)$ followed by self-employed (25.1\%), not employed (17.9\%) and $10.2 \%$ employed as government servant. Most respondents have income more than RM4000 and respondents with no stable income are $24.3 \%$. Based on the survey, most respondents are from Sri Gading whom has stayed in for more than 10 years lead by $57 \%$ followed by 6 to 10 years $(29.7 \%)$.

Descriptive statistics are represented to measures the tendency and frequencies of each item. Table VI shows the results obtained from the survey questionnaire. The results show the percentage for each layer of the proposed model of a smart city that has been shown in Fig. 2.

Based on Table VI, the descriptive statistics, and variables for four elements of a smart city are summarized for its mean value. Table VII shows the mean for each layers of the proposed model of a smart city. The average mean for infrastructure is 4.24; IOTs is 4.21; Environment is 4.30 and Culture is 4.15 .

Based on Table VII, the mean of distribution is greater than 4 out of 5 . Hence, this verified the requirements of the model of a smart city model based on Table VII. That is, firstly, a smart city should have infrastructure which consists of hospital, school, recreation park and library. Secondly, IoTs installation in the smart city such as Wi-Fi, CCTV, Smart Parking and RFID are needed as well. Thirdly, environment should also be recognized as one of a smart city element that includes waste management, renewable resource energy, water management, and recycling program. Lastly, the culture element is considered as well such as prayer places and a town hall. The urban district should have these four elements in order for the urban district to be transformed into smart city as shown in Fig. 2.

TABLE V. DEMOGRAPHIC INFORMATION

\begin{tabular}{|c|c|c|c|c|c|}
\hline Item & Categories & Frequency & Percent & Valid Percent & Cumulative Percent \\
\hline \multirow{2}{*}{ Gender } & Male & 151 & 40.4 & 40.4 & 40.4 \\
\hline & Female & 223 & 59.6 & 59.6 & 100.0 \\
\hline \multirow{4}{*}{ Race } & Malay & 344 & 92.0 & 92.0 & 92.0 \\
\hline & Chinese & 19 & 5.1 & 5.1 & 97.1 \\
\hline & Indian & 9 & 2.4 & 2.4 & 99.5 \\
\hline & Others & 2 & 0.5 & 0.5 & 100.0 \\
\hline \multirow{5}{*}{ Age (years) } & Under 20 & 32 & 8.6 & 8.6 & 8.6 \\
\hline & $21-30$ & 48 & 12.8 & 12.8 & 21.4 \\
\hline & $31-40$ & 91 & 24.3 & 24.3 & 45.7 \\
\hline & $41-50$ & 116 & 31.0 & 31.0 & 76.7 \\
\hline & $>50$ & 87 & 23.3 & 23.3 & 100.0 \\
\hline \multirow{5}{*}{ Occupation } & Government & 38 & 10.2 & 10.2 & 10.2 \\
\hline & Private Sector & 139 & 37.2 & 37.2 & 47.3 \\
\hline & Self-employed & 94 & 25.1 & 25.1 & 72.5 \\
\hline & Student & 36 & 9.6 & 9.6 & 82.1 \\
\hline & Not employed & 67 & 17.9 & 17.9 & 100.0 \\
\hline \multirow{6}{*}{ Income (RM) } & $100-1000$ & 70 & 18.7 & 18.7 & 18.7 \\
\hline & $1001-2000$ & 103 & 27.5 & 27.5 & 46.3 \\
\hline & $2001-3000$ & 59 & 15.8 & 15.8 & 62.0 \\
\hline & $3001-4000$ & 18 & 4.8 & 4.8 & 66.8 \\
\hline & $>4000$ & 33 & 8.8 & 8.8 & 75.7 \\
\hline & No income & 91 & 24.3 & 24.3 & 100.0 \\
\hline \multirow{4}{*}{ Residency } & $<1$ & 18 & 4.8 & 4.8 & 4.8 \\
\hline & $1-5$ & 32 & 8.6 & 8.6 & 13.4 \\
\hline & $6-10$ & 111 & 29.7 & 29.7 & 43.0 \\
\hline & $>10$ & 213 & 57.0 & 57.0 & 100.0 \\
\hline
\end{tabular}


TABLE VI. RESULTS BASED ON SURVEY QUESTIONNAIRE

\begin{tabular}{|c|c|c|c|c|c|c|}
\hline Elements & Items & Strongly Agree (\%) & Agree (\%) & Neutral (\%) & Disagree (\%) & Strongly Disagree (\%) \\
\hline \multirow{4}{*}{ Infrastructure } & Hospital & 44.65 & 39.84 & 14.17 & 0.80 & 0.53 \\
\hline & School & 43.65 & 43.85 & 11.23 & 0.80 & 0.53 \\
\hline & Recreation Park & 33.69 & 54.01 & 8.82 & 3.21 & 0.27 \\
\hline & Library & 38.50 & 48.65 & 10.43 & 1.87 & 0.53 \\
\hline \multirow{4}{*}{ IoTS } & WSN WiFI & 44.25 & 44.26 & 9.63 & 1.07 & 0.60 \\
\hline & CCTV & 41.44 & 47.33 & 9.63 & 1.07 & 0.53 \\
\hline & Smart Parking & 40.37 & 43.58 & 13.90 & 1.34 & 0.80 \\
\hline & RFID & 32.62 & 47.33 & 15.78 & 3.48 & 0.80 \\
\hline \multirow{4}{*}{ Environment } & Waste Management & 39.57 & 47.33 & 11.50 & 0.80 & 0.80 \\
\hline & Renewable Resource Energy & 33.96 & 48.13 & 16.04 & 1.34 & 0.53 \\
\hline & Water Management & 41.44 & 47.33 & 9.63 & 1.07 & 0.53 \\
\hline & Recycling Program & 40.47 & 48.66 & 9.09 & 0.80 & 1.07 \\
\hline \multirow{2}{*}{ Culture } & Prayer Place & 38.77 & 43.58 & 14.71 & 1.87 & 1.07 \\
\hline & Town Hall & 34.76 & 45.99 & 16.31 & 2.41 & 0.53 \\
\hline
\end{tabular}

TABLE VII. THE MEAN For EACH ELEMENT

\begin{tabular}{|c|c|c|c|}
\hline Elements & Items & Mean & $\begin{array}{l}\text { Average } \\
\text { Mean }\end{array}$ \\
\hline \multirow{4}{*}{ Infrastructure } & Hospital & 4.27 & \multirow{4}{*}{4.24} \\
\hline & School & 4.29 & \\
\hline & Recreation Park & 4.18 & \\
\hline & Library & 4.23 & \\
\hline \multirow{4}{*}{ IOTS } & WSN WiFI & 4.28 & \multirow{4}{*}{4.21} \\
\hline & CCTV & 4.28 & \\
\hline & Smart Parking & 4.21 & \\
\hline & RFID & 4.07 & \\
\hline \multirow{4}{*}{ Environment } & Waste Management & 4.24 & \multirow{4}{*}{4.30} \\
\hline & Renewable Resource Energy & 4.14 & \\
\hline & Water Management & 4.28 & \\
\hline & Recycling Program & 4.26 & \\
\hline \multirow{2}{*}{ Culture } & Prayer Place & 4.17 & \multirow{2}{*}{4.15} \\
\hline & Town Hall & 4.12 & \\
\hline
\end{tabular}

\section{COMPARISON AND DISCUSSION}

The comparison of smart city model between Dubai, Brisbane, and Putrajaya had been made by reviewing some papers from various sources such as [2, 3, 4, 5, 24, 25].

Dubai as the fastest growing city has amazed the world by their vigorous movement towards an intelligent city. Dubai built its history in socio-economic, leading regional paradigm of digital transformation and sustaining the status of the city as a global hub. In six dimension of Dubai, Dubai municipalities has highlighted several elements such as health, infrastructure, transport, piped water, sanitation, electricity, road infrastructure, and building [24].
Brisbane is another example of a smart city. Brisbane is the second city in the world to implement a digital transformation strategy. With an eye towards a better city, Brisbane has introduced a smart, connected city concept for the purpose of delivering a more liveable, sustainable, and prosperous city. In the last few years, Brisbane municipality realised the opportunities of Brisbane in becoming an economic city that deliver the right environment for economic purpose in investment, collaboration, and growth. In order to do so, Brisbane [25] has presented six characteristics of its smart, connected city. Brisbane city council has highlighted transport, water, energy, telecommunications, waste management, social infrastructure, green space, and key district as main elements of Brisbane Smart City.

Meanwhile, Putrajaya is in progress of becoming the first smart city in Malaysia with the inclusion of Internet of Things (IoTs) and other information and communication technology (ICT) innovations as the main feature in building a global city. Putrajaya has a vision of transforming itself into a Green City by the year of 2025 [2]. In order to achieve the objective of becoming a smart city, Smart Putrajaya has highlighted the elements of Communication, Street \& Compound Lighting, Facilities Management, and Waste Management System as the main features in developing a smart city.

The urban district should have four elements in order to be transformed into a smart city as shown in Fig. 2. Table VIII shows the results of transformation of urban district (in the case of Sri Gading) into a smart city.

Based on Table VIII, Sri Gading has few elements that can be considered to be a smart city. However, elements such as hospital, library, CCTV, smart parking, RFID, renewable resource energy and a town hall building are needed in order to transform Sri Gading into a smart city. This kind of elements can be used as recommendations to higher authorities in order to transform Sri Gading into the future of a smart city. 
TABLE VIII. THE COMPARISON OF EACH ELEMENT

\begin{tabular}{|l|l|l|l|}
\hline \multirow{4}{*}{ Infrastructure } & Elements & $\begin{array}{l}\text { Sri } \\
\text { Grading }\end{array}$ & Smart City \\
\cline { 2 - 4 } & Hospital & No & Yes \\
\cline { 2 - 4 } & School & Yes & Yes \\
\cline { 2 - 4 } & Recreation Park & Yes & Yes \\
\cline { 2 - 4 } & Library & No & Yes \\
\hline \multirow{5}{*}{ IoTs } & Wi-Fi & Yes & Yes \\
\cline { 2 - 4 } & CCTV & No & Yes \\
\cline { 2 - 4 } & Smart Parking & No & Yes \\
\cline { 2 - 4 } & RFID & No & Yes \\
\hline \multirow{5}{*}{ Environment } & Waste Management & Yes & Yes \\
\cline { 2 - 4 } & Renewable Resource Energy & No & Yes \\
\cline { 2 - 4 } & Water management & Yes & Yes \\
\cline { 2 - 4 } & Recycling Program & Yes & Yes \\
\hline \multirow{5}{*}{ Culture } & Prayer Place & Yes & Yes \\
\cline { 2 - 4 } & Town Hall & No & Yes \\
\hline
\end{tabular}

\section{CONCLUSION AND FUTURE WORK}

This paper discussed requirements analysis for validation of transforming the urban district to a smart city. The results for the validation of requirements based on survey instrument are very promising. Based on the results, most respondents agreed that infrastructure, IoTs, environments and culture are the four vital elements for a model of a smart city. For future work, the model of a smart city presented in this paper can be used as a guideline for transformation of an urban district to a smart city. Recommendation can be made based on the guideline whether the city can be transformed into a smart city or not.

\section{ACKNOWLEDGMENT}

The authors would like to thank Ministry of Higher Education (MOHE) for supporting this research study under Fundamental Research Grant (FRGS) entitled: Designing a Model for Smart City thru Digital Transformation, under grant Vote No FRGS/1/2018/ICT04/UTHM/01/1.

\section{REFERENCES}

[1] S.P. Mohanty, U. Choppali and E. Kougianos, "Everything you wanted to know about smart cities: The Internet of things is the backbone," IEEE Consumer Electronics Magazine, vol. 5, no. 3, pp. 60-70, July 2016.

[2] Putrajaya Smart City, Putrajaya Smart City Blue Print, 2021. [Online]. Available: https://smart.putrajaya.my

[3] Malaysian Communications and Multimedia Commission. Framework on Smart Cities Standardisation in Relations to Information \& Communication Aspects, 2021. [Online]. Available: https://www.mcmc.gov.my/skmmgovmy/media/General/pdf/Framework -on-Smart-Cities-Standardisation.pdf

[4] R. Ibrahim, N.A.M. Asri and S. Jamel, "Utilization of IOTs in Developing the Architecture of Smart City in Malaysia," 2019 IEEE 9th
International Conference on System Engineering and Technology, ICSET 2019 - Proceeding, 2019, pp. 35-40, 8906398.

[5] R. Mehmood, B. Bhaiduri, I. Katib, "Smart Societies, Infrastructure, Technologies and Applications," First International Conference, SCITA, 2017, Jeddah, Saudi Arabia, November 27-29, Proceedings, 2017.

[6] European Commission Directorate, General for Research and Innovation, Towards an EU Research and Innovation Policy Agenda for Nature-Based Solutions and Re-Naturing Cities: Final Report of the Horizon 2020 Expert Group on 'Nature-Based Solutions and ReNaturing Cities, 2015. DOI:10.2777/479582

[7] R. Khatoun and S. Zeadally, "Smart cities." Communications of the ACM, 59(8), 46-57, 2016.

[8] U. Ahmad, J. Chaudhary, M. Ahmad and A. A. Naz, "Survey of Internet of Things (IoT) for Different Industry Environment," Annals of Emerging Technologies in Computing (AETiC) Vol. 3, No., 2019.

[9] Gartner Inc., Gartner says 4.9 billion connected things" will be in use in 2015. [Online]. Available: http://www.gartner.com/newsroom/id/29057 17, Nov 2014

[10] V. Chang, V. Kantere, M. Ramachandran, "Emerging services for internet of things," Journal Network Computing Appl. 89, 1-2, 2017.

[11] Y. Qian, D. Wu, W. Bao and P. Lorenz, "The Internet of Things for Smart Cities: Technologies and Applications," IEEE NetworkMarch/April 2019.

[12] S. Zygiaris, "Smart City Reference Model: Assisting Planners to Conceptualize the Building of Smart City Innovation Ecosystems," Journal of the Knowledge Economy, 4(2), 217-231, 2012.

[13] G. A. Tangauay, J. Rajaonson, J. Lefebreve and P. Lanoie, "Measuring the Sustainability of Cities: A Survey-based analysis of the Use of Local Indicators". SSRN Electronic Journal. 2010. DOI:10.2139/ssrn.1336649

[14] P. Neirotti, A. De Marco, A. C. Cagliano, G. Mangano and F. Scorrano, "Current trends in Smart City initiatives: Some stylised facts." Cities, 38, 25-36, 2014.

[15] Z. Allam and P. Newman, "Redefining the Smart City: Culture, Metabolism and Governance”. Smart Cities, 1(1), 4-25, 2018

[16] McNamara, Carter, General Guidelines for Conducting Interviews. 1999. [Online]. Available: https://managementhelp.org/business research/interviews.htm

[17] S. Giacoppo, "Development Methods: User Needs Assessment \& Task Analyses." Department of Psychology, Catholic University, 2001.

[18] B. Earl, "Survey Research Methods", Second Edition. California: Wadsworth Publishing Company, 1990.

[19] R. L. Armstrong, "The Midpoint on a Five-Point Likert-Type Scale." Perceptual and Motor Skills, 64(2), 359362. doi:10.2466/pms.1987.64.2.359, 1987.

[20] J. W. Creswell, "Planning, Conducting, and Evaluating Quantitative and Qualitative Research.” University of Nebraska-Lincoln, 2012.

[21] L. J. Cronbach, "Response sets and test validity." Educational and Physocological Measurement 6(4): pp 475-494, 1946.

[22] L. Tabachnick and F. Fidell, "Using Multivariate Statistics."Pearson Education Inc. Vol. 28, 2017.

[23] S.P. Holmes, L. Coote and E. Cunningham, "Structural Equation and Modelling: From the fundamentals to advanced topics." Melbourne:Stream, 2006.

[24] Abdulla bin Hozaim and Vishwesh Laxmikant, "A Framework for transforming Dubai into a smart city." The Fourth HCT Information Technology Trends (ITT 2017) Dubai, UAE, Oct 25-26, 2017.

[25] Digital Brisbane. Digital Brisbane 2.0- Empowering residents and businesses to thrive globally-connected, digitally-enabled world. [Online]. Available: https://www.brisbane.qld.gov.au/aboutcouncil/governance-and-strategy/vision-and-strategy/smart-connectedbrisbane 